\title{
Sequência Didática: Nas Ondas das Partículas Elementares. Uma Proposta de Ensino de Física Moderna e Contemporânea aos estudantes da Rede Pública Estadual
}

\author{
Silva, T. P.; Fogos, W. F.; Santos, D. A. S. \\ 1 Centro Estadual de Ensino Médio em Tempo Integral São Pedro, Vitória, ES, Brasil.
}

*e-mail: thiagopereiradasilva@yahoo.com.br

\begin{abstract}
Resumo
O trabalho apresenta os resultados de uma Sequência Didática intitulada "Nas Ondas das Partículas Elementares" aplicada em 25 alunos do ensino médio de uma escola da Rede Pública Estadual. 0 objetivo da Sequência Didática foi mostrar aos alunos como a Ciência é dinâmica, como ela se desenvolve, a contribuição de diferentes cientistas para se chegar a um conceito e como a experimentação se tornam crucial e difícil de ser realizada, sendo necessário o investimento financeiro e cooperativo de diversos países e cientistas. Foram 19 encontros ao longo dos meses de Agosto a Novembro. Em cada encontro, uma atividade era realizada seguida de um debate. Inicialmente os alunos responderam a um questionário inicial para verificação das concepções prévias. Após aplicação do questionário, demos o início das atividades da Sequência Didática. Ao término da execução das atividades, nota-se uma mudança das concepções prévias dos alunos a respeito do mundo atômico e a ampliação da sua visão de mundo quando comparado os questionários inicial e final.
\end{abstract}

\begin{abstract}
The paper presents the results of a Didactic Sequence entitled "In the Waves of Elementary Particles" applied in 25 high school students of a State Public School. The purpose of the Didactic Sequence was to show students how science is dynamic, how it develops, the contribution of different scientists to arrive at a concept and how experimentation becomes crucial and difficult to be accomplished, requiring financial investment and cooperative of different countries and scientists. There were 19 meetings during the months of August to November. At each meeting, an activity was held followed by a discussion. Initially the students answered an initial questionnaire to verify the previous conceptions. After application of the questionnaire, we started the activities of the Didactic Sequence. At the end of the activities, there is a change in students' previous conceptions about the atomic world and the expansion of their world view when compared to the initial and final questionnaires.
\end{abstract}

Keywords (Palavras chaves): Ensino de Física, Partículas Elementares, Sequência Didática.

\section{Introdução}

O intuito da Sequência Didática foi apresentar a Física Moderna e Contemporânea aos alunos do Ensino Médio de uma escola pública estadual. As atividades ocorreram entre os meses de agosto e novembro de 2016. Ao todo, participaram do projeto, 25 estudantes.
Segundo SIQUEIRA (2006) a Física de Partículas torna-se um conteúdo adequado para explicar o processo científico de validação de teorias, bem como o funcionamento da Ciência atual na busca pela compreensão da natureza. Observa-se que há um movimento de inserção de conteúdos de Física Moderna e Contemporânea nos currículos de Física do ensino básico. Porém, as pesquisas acerca do ensino 
de Física de Partículas, para estudantes do Ensino Médio, ainda são poucas em comparação com outros tópicos curriculares da Física. De acordo com ARAÚJO e LOUZADA (2006), apresentar o conteúdo de Física de Partículas Elementares no Ensino Médio constitui, sem dúvida, um desafio, uma vez que os tópicos de Física Moderna e Contemporânea não foram inseridos efetivamente nos currículos e o número de aulas semanais de Física, na maior parte das escolas, ainda é muito reduzido. Nos Parâmetros Curriculares Nacionais (PCN), afirmam que, alguns aspectos da chamada Física Moderna serão indispensáveis para permitir aos jovens adquirir uma compreensão mais abrangente sobre como se constitui a matéria, de forma que tenham contato com diferentes e novos materiais, cristais líquidos e lasers, presentes nos utensílios tecnológicos, ou com o desenvolvimento da eletrônica, dos circuitos integrados e dos microprocessadores. A compreensão dos modelos para a constituição da matéria deve, ainda, incluir as interações no núcleo dos átomos e os modelos que a ciência hoje propõe para um mundo povoado de partículas. Mas será também indispensável ir mais além, aprendendo a identificar, lidar e reconhecer as radiações e seus diferentes usos.

\section{Metodologia}

A Sequência Didática, apresentada aos estudantes, foi baseada no site $A$ aventura das Partículas, disponível em sprace.org.br/AventuraDasPartículas. Os estudantes foram incentivados a lerem, ao longo do projeto, o artigo "Sobre o Discreto Charme das Partículas Elementares", da professora Maria Cristina Batoni Abdalla. A Sequência Didática foi composta da seguinte forma:

- Aplicação de um questionário inicial;

- O que é fundamental? Do que o mundo é feito?

- O que mantém unido? Decaimento das Partículas.

- Mistérios não resolvido.

Essas discussões tentaram apresentar o Modelo Padrão. As próximas atividades, tentaram discutir sobre as evidencias experimentais do Modelo Padrão.

- Como podemos conhecer algo sobre isto? Como podemos detectar o que está acontecendo?

- Como fazemos experimentos com partículas minúsculas? Como interpretamos nossos dados?

- Confecção de mapa conceitual.

Ao longo do desenvolvimento do projeto, tivemos a participação de professores dos Departamentos de Física e da Química da Universidade Federal do Espírito Santo que prontamente, ao receberem o convite, vieram até a escola e apresentaram um colóquio sobre os seguintes tópicos:
- Albert Einstein;

- Quimiluminescência;

- Matéria Escura e Energia Escura;

- Dimensões Atômicas;

- OLHC;

Os encontros semanais da eletiva foram extremamente riquíssimos e os resultados extremamente proveitosos, que acabaram numa culminância, no mês de novembro, em um roteiro teatral intitulado "Nas ondas das Partículas Elementares".

Inicialmente os alunos responderam um questionário inicial para verificar o conhecimento prévio a respeito do mundo microscópico. O conhecimento prévio, segundo AUSUBEL (2003), é o que o aluno já sabe, a ideia-âncora, ou subsunçor, é a ponte para a construção de um novo conhecimento por meio da reconfiguração das estruturas mentais existentes ou da elaboração de outras novas. Após a aplicação do questionário, deu-se início a aplicação das atividades da Sequência Didática, intitulada "Nas ondas das Partículas Elementares". A sequência seguiu as seguintes atividades. Cada atividade, equivale a um encontro, de aproximadamente, 1h40min.:

1. "Do que o mundo é feito? "; "O que o mantém unido?"; O significado da palavra "fundamental"; O Átomo; O núcleo é "fundamental"?; Os prótons e os nêutrons são "fundamentais"?; A escala do Átomo; O modelo padrão.

2. Realizamos uma atividade prática tentando estabelecer em escala real de distâncias o tamanho de um átomo.

3. O que é antimatéria?; Os quarks; hádrons, bários e mésons; Os léptons; Decaimento dos léptons; Os neutrinos; A geração de matéria;

4. Apresentamos o físico César Lattes.

5. Discutimos sobre as quatro interações; Força versus interação; Como a matéria interage?;

6. Tivemos a ilustre presença de um professor do Departamento de Física da Universidade Federal do Espírito Santo que apresentou a vida e a obra de Albert Einstein.

7. O tópico foi o eletromagnetismo; O núcleo?; $\mathrm{A}$ força forte; A força fraca.

8. Tivemos a presença de uma professora do Departamento de Química da Universidade Federal do Espírito Santo que apresentou os fenômenos da Quimiluminescência.

9. Conversamos sobre a gravidade e a possibilidade de uma partícula o gráviton; Mecânica Quântica; O Princípio da Exclusão de Pauli; Férmions e Bósons.

10. Participamos de uma conversa com um professor do Departamento de Física da Universidade Federal do Espírito Santo sobre a Matéria Escura e a Energia Escura. 
11. O debate foi sobre o decaimento; Radioatividade; Partículas radioativas; Meia vida; Massa perdida; Medidores do decaimento de partícula; Interações diferentes; Aniquilações e exemplos de decaimentos.

12. O tema da abordado foi Testando uma Teoria; Pesquisando a Estrutura do Átomo; O Resultado de Rutherford; A Análise de Rutherford; Como os Físicos Experimentam.

13. O encontro se deu em torno da seguinte questão: Como podemos detectar o que está acontecendo? Assim discutimos sobre microscópio; Os aceleradores, escalas, massa e energia; Como funcionam os aceleradores; Como os físicos obtêm as partículas que querem estudar?

14. Recebemos a visita de um professor do Departamento de Física da Universidade Federal do Espírito Santo que conversou sobre as dimensões atômicas.

15. Conversamos a respeito dos detectores; As formas dos detectores; Os detectores modernos; Os componentes típicos de um detector; Reconstrução computadorizada de um evento.

16. Recebemos a visita de um professor do Departamento de Física da Universidade Federal do Espírito Santo que apresentou o tema LHC.

17. Os alunos foram convidados a apresentarem à comunidade escolar o que foi aprendido. Ficou definido, por eles, a apresentação de um teatro. Deu-se início a execução de um roteiro.

18. Os estudantes finalizaram o roteiro, intitulado "Nas ondas das partículas elementares" e ensaiaram.

19. Foi realizada uma atividade de confecção de um mapa conceitual, finalizando as atividades da sequência didática. A execução do teatro ocorreu na semana seguinte.

Um estudo comparativo dos dados coletados no questionário inicial, juntamente com o mapa conceitual e somadas as atividades realizadas durante a sequência didática, foi possível constatar uma possível mudança ou fortalecimento dos conhecimentos prévios dos estudantes à respeito dos modelos atômicos.

\section{Resultados e Discussões}

No questionário inicial, quando indagados com a seguinte pergunta: "O átomo é a menor estrutura conhecida e não pode ser dividida? ". A tabela 1 indica o percentual das respostas.

\begin{tabular}{|l|l|} 
Respostas & Percentual \\
\hline
\end{tabular}

\begin{tabular}{|l|c|}
\hline $\begin{array}{l}\text { Não, e citam elétrons e } \\
\text { prótons. }\end{array}$ & (2) $8 \%$ \\
\hline $\begin{array}{l}\text { Não, e citam elétrons, } \\
\text { prótons e nêutrons. }\end{array}$ & (6) $24 \%$ \\
\hline $\begin{array}{l}\text { Sim, é a menor } \\
\text { estrutura. pitam } \\
\text { elétrons, prótons e } \\
\text { nêutrons. }\end{array}$ & (8) $8 \%$ \\
\hline $\begin{array}{l}\text { Não, e não cita } \\
\text { nenhuma partícula. }\end{array}$ & (7) $28 \%$ \\
\hline Não responderam. & \\
\hline
\end{tabular}

Tabela 1: Respostas dos alunos a pergunta "O átomo é a menor estrutura conhecida e não pode ser dividida?".

Observa-se que $32 \%$ dos estudantes citam o átomo como a menor estrutura do seu universo conhecido e ainda possuem um conhecimento do modelo atômico esperado por estudantes do Ensino Médio. Possivelmente, esses valores estejam associados a uma aprendizagem puramente livresca e mecânica. $\mathrm{Na}$ pergunta: "Você conhece, ou já ouviu falar, de Léptons e Quarks?", a tabela 2 indica o percentual de respostas:

\begin{tabular}{|c|c|}
\hline Sim & (3) $12 \%$ \\
\hline Não & (22) $88 \%$ \\
\hline
\end{tabular}

Tabela 2: Respostas dos alunos a pergunta "Você conhece, ou já ouviu falar, de Léptons e Quarks?".

Percebemos que $88 \%$ dos estudantes não possuíam qualquer conhecimento sistematizado sobre Física de Partículas. Isso pode ser justificado pelo fato de que o tópico, Física de Partícula, não faz parte do programa curricular de Física das escolas. Possivelmente, os $12 \%$ dos alunos que indicaram ter conhecimento dos Léptons e Quarks, tenham adquirido essas informações por meio do ensino não-formal. Quando o aluno foi perguntado com o seguinte questionamento: "Você conhece ou já ouviu falar de aceleradores de partículas? ". A tabela 3 informa o percentual de respostas:

\begin{tabular}{|c|c|}
\hline Sim & (3) $12 \%$ \\
\hline Não & (22) $88 \%$ \\
\hline
\end{tabular}

Tabela 3: Respostas dos alunos a pergunta "Você conhece ou já ouviu falar de aceleradores de partículas?".

Ao todo, três alunos indicaram conhecer ou já ter ouvido dos aceleradores de partículas. Possivelmente, os alunos lembraram-se dos noticiários a respeito da confirmação do Bóson de Higgs, ocorrida no ano de 2013.

No decorrer da sequência didática, os estudantes foram convidados a lerem o artigo "Sobre o Discreto 
Charme das Partículas Elementares". Para ZANOTELLO e ALMEIDA (2007), a leitura de textos de divulgação científica se constitui em uma atividade diferenciada em relação ao desenvolvimento das aulas de Física. Percebemos ainda, que parte dos estudantes participantes da eletiva não estava habituada com práticas de leitura, pois encontramos forte resistência na realização dessa atividade. Ao analisar os mapas conceituais, tabela 4, comparando com os dados do questionário inicial, observou-se, uma mudança das concepções prévias. Segundo MOREIRA (1983) os mapas conceituais são bons instrumentos para representar a estrutura cognitiva do aluno, averiguando além dos subsunçores (o que o aluno já conhece) existentes, as mudanças que ocorrem na estrutura cognitiva durante a instrução.

\begin{tabular}{|c|c|}
\hline Mapas Conceituais & Percentual (\%) \\
\hline $\begin{array}{l}\text { Indicaram o átomo, como } \\
\text { uma estrutura formada } \\
\text { por elétrons, prótons e } \\
\text { nêutrons. }\end{array}$ & (25) $100 \%$ \\
\hline $\begin{array}{l}\text { Indicaram a estrutura } \\
\text { atômica com as } \\
\text { partículas } \\
\text { Léptons e Quarks }\end{array}$ & (18) $72 \%$ \\
\hline
\end{tabular}

Após a execução de toda a sequência didática, os estudantes compreenderam que o átomo é uma unidade básica de matéria, formada por elétrons, prótons e nêutrons. Observamos que $72 \%$ dos alunos vislumbraram a existência de partículas menores que os átomos, menores que os prótons e ainda, que essas partículas, são formadoras dos prótons e dos nêutrons. Comparando as respostas dos questionários iniciais com as informações dos mapas conceituais, podemos evidenciar uma mudança das concepções prévias dos estudantes. O modelo atômico de Rutherford-Bohr, apresentado aos estudantes do Ensino Fundamental Séries Finais e do Ensino Médio, que antes era reconhecido por $32 \%$ (tabela 1) agora passou a ser reconhecido por $100 \%$ (tabela 4). O subsunçor relacionado ao modelo atômico tornou-se mais diferenciado com os novos conhecimentos da Física Contemporânea Moderna, $72 \%$ dos estudantes indicaram na sua resposta (tabela 4) as partículas elementares Léptons e Quarks.

Segundo MOREIRA (2012), o subsunçor pode ter maior ou menor estabilidade cognitiva, pode estar mais ou menos diferenciado, ou seja, mais ou menos elaborado em termos significados. Fato verificado na tabela 1. Ainda segundo MOREIRA (2012), os novos conhecimentos adquirem significado para o sujeito e os conhecimentos prévios adquirem novos significados ou maior estabilidade cognitiva. Fato evidenciado na tabela 4, o que demonstra uma mudança nos conhecimentos prévios.

\section{Conclusões}

Verificamos, ao longo das atividades da sequência didática, uma mudança atitudinal. Alunos buscaram fontes alternativas (além dos textos apresentados e dos links sugeridos). Outros, efetuaram a leitura do artigo "Sobre o Discreto Charme das Partículas Elementares" e discutiram o texto com o professor nos intervalos das aulas. Alunos fizeram o download do livro "Alice no país do Quantum" de Robert Gilmore. Segundo um aluno participante: "A eletiva me influenciou muito no despertar da ciência, e na minha decisão definitiva para o meu projeto profissional, quero estudar Física! Tenho agora outro conhecimento de mundo". Essencialmente, a sequência didática demonstrou um bom material didático e de divulgação científica. O comparativo dos dados iniciais e finais, apontam para uma mudança das concepções prévias em torno do modelo atômico. Segundo um aluno: "A participação despertou um sentido crítico, visto que o modelo atômico, entre outras coisas, não são exatamente o que é ensinado durante toda a minha vida escolar". Como divulgador científico, ela apresentou um tópico da Física Moderna Contemporânea, ampliando o conhecimento científico dos participantes. Esse fato fica claro, no relato do aluno: "O teatro partiu de criação dos próprios alunos, tal como seu funcionamento e conceitos nele apresentado. $O$ intuito foi difundir de forma prática $e$ acessivel a todos os curiosos, interessados e desinteressados da escola o mundo das partículas elementares". A sequência didática, apresentada aos alunos, aparenta ser um bom material aos professores da rede pública estadual que queiram introduzir um debate sobre Partículas Elementares na sua escola.

\section{Agradecimentos}

Aos alunos participantes da eletiva "Nas Ondas das Partículas Elementares" do Centro Estadual de Ensino Médio em Tempo Integral São Pedro (CEEMTI São Pedro); a professora Priscilla Paiva Luz e aos professores José Alexandre Nogueira, Laércio Evandro Ferracioli da Silva, Hermano Velten e André Oakes de Oliveira Gonçalves pelo inestimável tempo cedido ao projeto.

\section{Referências}

\section{Artigos}

[1] ABDALA, M. C. O discreto charme das partículas elementares. São Paulo: UNESP, 2006.

[2] ARAÚJO, M. S.; LOZADA, C. O. Ensino de Física de PArtículas Elementares no Ensino Médio: as perspectivas dos professors em relação ao Ensino do Modelo Padrão. São Paulo: Universidade do Cruzeiro do Sul, 2006. 
[3] MOREIRA, M. A. O que é afinal aprendizagem significativa?. Qurriculum, La Laguna, Espanha, 2012.

[4] SIQUEIRA, M. R. P. Do visível ao indivisivel: uma proposta de Física de Partículas Elementares para o Ensino Médio. São Paulo: Universidade de São Paulo, 2006.

[5] ZANOTELLO, M.; ALMEIDA, M. J. P. M. Produção de sentidos e possibilidades de medição na Física do Ensino médio: leitura de um livro sobre Isaac Newton. Revista Brasielira de Ensino de Física, v.29, n.3, p.437446, 2007.

\section{Livros}

[5] BRASIL. (2002). Ministério da Educação. PCN+ Ensino Médio: Orientações Complementares aos Parâmetros Curriculares nacionais para o Ensino Médio. Ciências da Natureza, Matemática e suas tecnologias. Brasília.
[6] AUSUBEL, D.P. Aquisição e retenção de conhecimentos. Lisboa: Plátano Edições Técnicas, 2003.

[7] MOREIRA, M. A. Uma abordagem cognitivista ao Ensino de Física. Porto Alegre: Editora da Universidade, 1983.

\section{Página de internet}

[7] A aventura das Partículas. Disponível em <https://www.sprace.org.br/AventuraDasParticulas/>. Acesso em: 10 Agosto. 2017. 